\title{
Map and Tables
}

Map 1 San Francisco Circa 1855

2

Table I Growth of Population in San Francisco and Oakland, 1852-1900

Table 2 Assessed Valuation of San Francisco, 1860-1890 14

Table 3 U.S. Cities and Their Black Population, 1900

Table 4 Growth of U.S. Cities and Their Black Population, 1900-1940

Table 5 Origins of San Francisco's Black Residents, 1860 and 1900

Table 6 Ratio of Males to Females, for Total Population and for Black Residents, San Francisco, 1860-1930

Table 7 U.S. and San Francisco Enumerations, by Color and by Ward, 1870

Table 8 Growth of Bay Area Black Population, by City, 1940-1950 
